\title{
Incidental Follicular Lymphoma in Duodenum After Routine Biopsy
}

\author{
Hamza Altaie ${ }^{1}$, Alhareth Alsagban ${ }^{1}$, Marwah A. Algodi ${ }^{1} \&$ Nisar Ahmed ${ }^{1}$ \\ ${ }^{1}$ Department of Gastroenterology, Park Plaza Hospital, Houston, TX 77004 USA \\ Correspondence: Nisar Ahmed, Department of Gastroenterology, Park Plaza Hospital, Houston, TX 77004 USA. \\ E-Mail: Altaie.hamza@yahoo.com,_Alharthsagban@gmail.com, Dr.marwa.aljudi@gmail.com, \\ Nisarahmedmd@yahoo.com
}

Received: April 26, 2018; Accepted: May 28, 2018; Published: June 22, 2018

\begin{abstract}
We describe a case of primary follicular lymphoma of duodenum (PFL-D) discovered during Esophagogastroduodenoscopy (EGD) in a patient with an unremarkable past medical history, where Histopathology and Immunohisto-chemical staining all were consistent with follicular lymphoma of duodenum. Patient was referred to a hematologist-oncologist for further evaluation and management. To the best of our knowledge, this is one of the rarest cases reported in English literature of (PFL-D) that present with both the nodular lesions and the erosions together.
\end{abstract}

Keywords: Primary Follicular Lymphoma of duodenum, nodular lesions, erosions, lymph nodes, Esophagogastroduodenscopy, Diffuse Large B-cell Lymphoma, Mucosa-associated Lymphoid Tissue

\section{Introduction}

Follicular lymphoma (FL) is a neoplasm that usually involves lymph nodes .Follicular lymphoma (FL) sorted as the second most common type of Non-Hodgkin lymphoma (NHL) in the United States, and makes up approximately $70 \%$ of all indolent (NHL) cases (Jemal et al. 2011). Of Follicular Lymphoma, the Primary Gastrointestinal Follicular Lymphoma (GI-FL) is an uncommon variant (Who Classification of Tumours of Haematopoietic and Lymphoid Tissues. 2018). Among (GI-FL), Follicular Lymphoma which occur in duodenum was mentioned individually as primary FL of the duodenum (PFL-D) for its interesting slothful course of progression. PFL-D regularly includes the duodenum second part, and it has been detailed to have a real preferable prognosis, indeed even without any treatment (Ana-Iris et al. 2011). PFL-D mostly presented with multiple nodules were the predominant endoscopic feature accounting for 80-89\% of patients with gastrointestinal follicular lymphoma (Yamamoto, Nakase \& Yamashita, 2010; Takata et al. 2011). PFL-D should not be under, or over diagnosed. Although Nodular lesion is the most common presentation and Erosions is the rarest one (Yamamoto, Nakase \& Yamashita, 2010; Takata et al. 2011). Etiology for follicular lymphoma has been noted to be really unknown and poorly understood (Zhang et al. 2011) while risk factors towards developing such tumor was linked to many different factors of which the researchers from the United States university of Yale has said that smoking cigeratte for long term has increased the risk of developing follicular lymphoma (Morton et al. 2005). Herein we present our experience of PFL-D case with macroscopical feature of Nodular mucosal lesions and Erosions.

\section{Case Report}

59 years old African American female referred to us for evaluation of recurrent abdominal pain failed to responds to acid suppression therapy. Physical examination was negative except for mild epigastric tenderness. Esophagogastroduodenoscopy (EGD) done for evaluation showed nodular mucosa with erosions of proximal duodenum. Histo-pathology revealed prominent lymphoid aggregates. Immunohisto-chemical staining ( CD 20CD 10- BCL6-BCL 2 ) all were consistent with duodenal-type Follicular Lymphoma. Patient was referred to a hematologist- oncologist for further evaluation and management.

\section{Discussion}

Primary FL of the Gastrointestinal tract occurs most frequently in middle-aged adult with a 2:1 female dominance. The foremost involved location of association is the duodenum, taken after by the ileum and colon. Obstruction of bowel that require surgical intervention is the presentation when the distal small bowel being involved. In the tremendous larger part of cases the disease is localized to the bowel and regional lymph nodes (Misdraji et al. 2011). Difficulties seen with initiating the comparison between PFL-D and reactive lymphoid hyperplasia or other 
B-cell lymphomas . Neoplastic follicles in PFL-D lack for the tingible bodies in macrophages that characterize the normal Follicles. Superiority of Centrocyte that missing the typical polarization considered as second characterization of neoplastic follicule (Takata et al. 2014). In Non-Hodgkin lymphoma; the most common extranodal types in GIT involvement are diffuse large B-cell lymphoma (DLBCL) and extranodal marginal zone lymphoma of mucosa-associated lymphoid tissue (MALT lymphoma). The ease is the way when trying to set the difference between DLBCL that has the diffuse infiltration of atypical lymphoid cells from PFL-D and in the meanwhile MALT lymphoma also exhibits lymphoepithelial lesions and it is from the rarity to show nodules. A discriminatory characteristic of PFL-D is the unparalleled appearance as white enlarged villi or white spots that differ in their sizes as seen endoscopically (Iwamuro et al. 2015). Although immunohistochemical phenotypes, histological and molecular aspects have many in common to say about in between PFL-D and Nodular FL ; Distinguishing features for both are always there (Ana-Iris et al. 2011). Low-grade (grade 1-2) has been solely encountered for PFL-D and high grade (grade 3) seen in 10\%-20\% of Nodal FL from histological point of view specified the difference in between (Who Classification of Tumours of Haematopoietic and Lymphoid Tissues. 2018; Kodama et al. 2007).

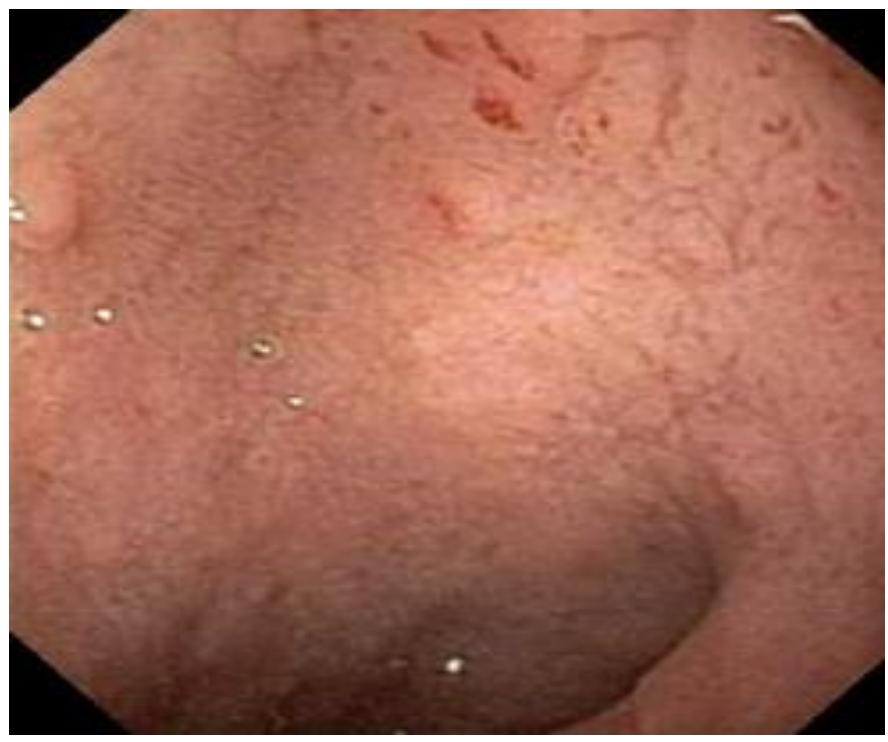

Figure 1. Endoscopic image showing nodular mucosa and erosions in the second part of the duodenum

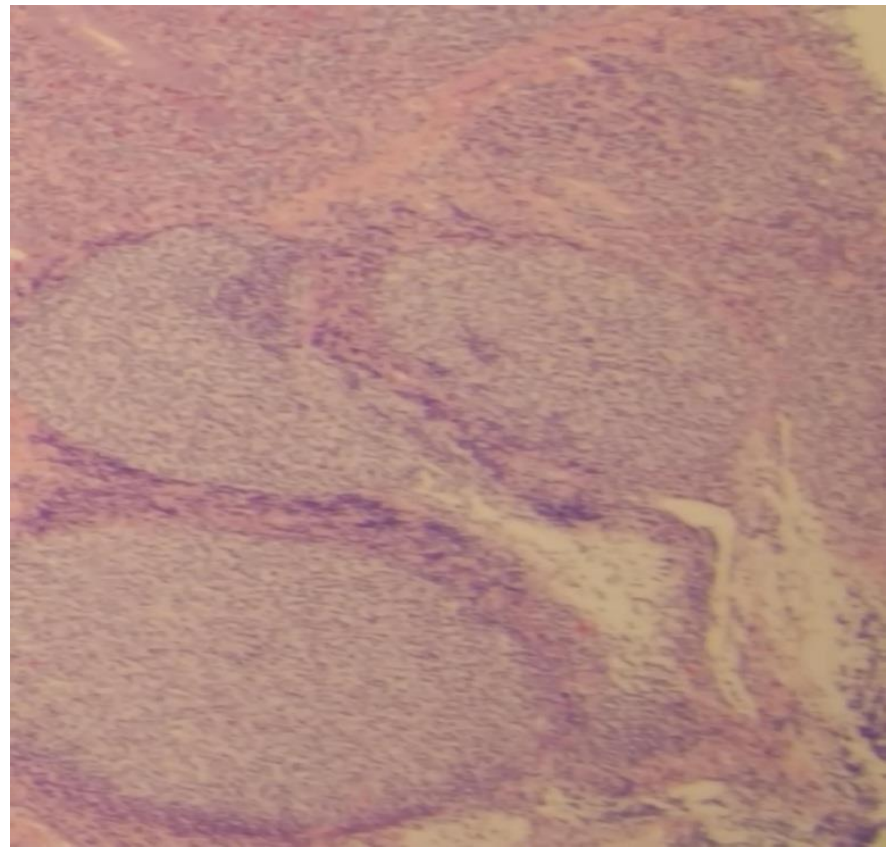

Figure 2A. Biopsy showed Follicular Lymphoma 


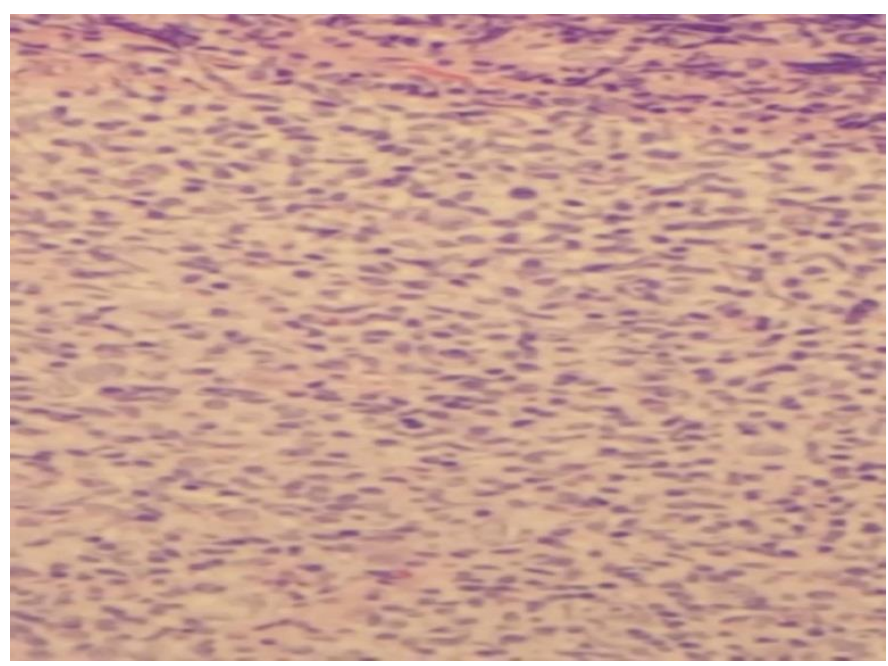

Figure 2B. On High Power field

\section{Conclusion}

Despite rarity ,sorting the differential diagnosis of duodenal multi-nodular lesions and / or erosions should include primary follicular lymphoma of the duodenum ,keeping PFL-D in mind can prevent missing the diagnosis and avoid aggressive treatment. So in patient with abdominal pain and signs of gastroesophageal reflux disease that is not responsive to antacid therapy ...We have to state PFL-D as a possibility.

\section{Refernces}

Ana-Iris, S., Berthold, S., Elisabeth, K. C. ,Andreas, P., Ulrich, J., Christine, M., Markus, T., German, O., Wolfgang, F., Peter, H., Gerhard, S., Manfred, S., Markus, R., \& Andreas, C. (2011). Primary Follicular Lymphoma of the Duodenum Is a Distinct Mucosal/Submucosal Variant of Follicular Lymphoma: A Retrospective Study of 63 Cases. Journal of Clinical Oncology, 29(11), 1445-451. https://doi.org/10.1200/jco.2010.32.9193

Bende, R. J., Laura, A. S., Janneke, G. B., Wilhelmina, M. A., Marcel, S., Laurence, D. L., Guy, E. E. B., Steven, T. P., \& Carel, J. M. V. N. (2003). Primary Follicular Lymphoma of the Small Intestine. The American Journal of Pathology, 162(1), 105-13. https://doi.org/10.1016/s0002-9440(10)63802-3

Bende, R. J., Smit, L. A., \& Van Noesel, C. J. M. (2006). Molecular Pathways in Follicular Lymphoma. Leukemia, 21(1), 18-29. https://doi.org/10.1038/sj.leu.2404426

Damaj, G. (2003). Primary Follicular Lymphoma of the Gastrointestinal Tract: A Study of 25 Cases and a Literature Review. Annals of Oncology, 14(4), 623-29. https://doi.org/10.1093/annonc/mdg168

Iwamuro, M., Okada, H., Takata, K, et al. (2015). Magnified endoscopic features of duodenal follicular lymphoma and other whitish lesions. Acta Med Okayama, 69, 37-44. https://doi.org/10.18926/AMO/53120

Jemal, A., Freddie, B., Melissa, M. C., Jacques, F., Elizabeth, W., \& David, F. (2011). Global Cancer Statistics. CA: A Cancer Journal for Clinicians, 61(2), 69-90. https://doi.org/10.3322/caac.20107

Kodama, M., Kitadai, Y., Shishido, T., Shimamoto, M., Fukumoto, A., Masuda, H., Tanaka, S., Yoshihara, M., Sakai, A., Nakayama, H., \& Chayama, K. (2007). Primary Follicular Lymphoma of the Gastrointestinal Tract: A Retrospective Case Series. Endoscopy, 40(4), 343-46. https://doi.org/10.1055/s-2007-995365

Misdraji, J., Harris, N. L., Hasserjian, R. P., Lauwers, G. Y., \& Ferry, J. A. (2011). Primary Follicular Lymphoma of the Gastrointestinal Tract. The American Journal of Surgical Pathology, 35(9), 1255-1263. https://doi.org/10.1097/PAS.0b013e318224e661

Morton, L. M., Zheng, T., Holford, T. R., et al. (2005). Alcohol consumption and risk of non-Hodgkin lymphoma: A pooled analysis. Lancet Oncol, 6(7), 469-476. https://doi.org/10.1016/S1470-2045(05)70214-X

Takata, K., Okada, H., Ohmiya, N., Nakamura, S., Kitadai, Y., Tari, A., \& Yoshino, T. (2011). Primary gastrointestinal follicular lymphoma involving the duodenal second portion is a distinct entity: A multicenter, retrospective analysis in Japan. Cancer Science, 102(8), 1532-1536. https://doi.org/10.1111/j.13497006.2011.01980.x

Takata, K., Tomoko, M. T., Yasuharu, S., \& Tadashi, Y. (2014). Pathology of Follicular Lymphoma. Journal of 
Clinical and Experimental Hematopathology, 54(1), 3-9. https://doi.org/10.3960/jslrt.54.3

Who Classification of Tumours of Haematopoietic and Lymphoid Tissues. (2018). World Health Organization. June 3, 2008. Retrieved April 17, 2018, from http://apps. who.int/bookorders/anglais/detart1.jsp?codlan=1\&codcol=70\&codcch=4002\&content=1

Yamamoto, S., Hiroshi, N., Kouhei, Y., Minoru, M., Mariko, T., Chiharu, K., \& Tsutomu, C. (2010). Gastrointestinal Follicular Lymphoma: Review of the Literature. Journal of Gastroenterology, 45(4), 370-88. Retrieved April 20, 2018, form https://doi.org/10.1007/s00535-009-0182-z

Yamamoto, S., Nakase, H., \& Yamashita, K. (2010). Gastrointestinal follicular lymphoma: Review of the literature. Journal of Gastroenterology, 45, 370-388. Retrieved March 20, 2018.

Zhang, Y., Dai, Y., Zheng, T., et al. (2011). Risk factors of Non-Hodgkin Lymphoma. Expert Opin Med Diagn, 5 , 539-550. Recent comprehensive review of NHL risk factors. https://doi.org/10.1517/17530059.2011.618185

\section{Copyrights}

Copyright for this article is retained by the author(s), with first publication rights granted to the journal.

This is an open-access article distributed under the terms and conditions of the Creative Commons Attribution license (http://creativecommons.org/licenses/by/4.0/). 